\title{
Espécies novas de Centris Fabricius (Hymenoptera, Apoidea) ${ }^{1}$
}

Jesus Santiago Moure ${ }^{2}$

\begin{abstract}
Aвstract. New species of Centris Fabricius (Hymenoptera, Apoidea). Three new species of Centris Fabricius, 1804 are described: C. (Melacentris) melanosara sp. nov. (Viçosa-MG, Brazil), C. (Ptilotopus) melampoda sp. nov. (Manaus-AM, Brazil), and C. (Ptilotopus) erythrotricha sp. nov. (Pucallpa, Peru). Centris (Melacentris) frieseana nom. nov., a new name given to Centris friesei Ducke, 1902, non Schrottky, 1902. Comments and comparison between C. (Melacentris) rhodoprocta Moure \& Seabra, 1961 and C. (Ptilotopus) nobilis Westwood, 1840, are given. All the species are figured.
\end{abstract}

KeYwords. Apoidea; Centris; Hymenoptera; Neotropical bees; taxonomy.

\section{INTRODUÇÃO}

Neste trabalho são propostas três espécies novas de Centris Fabricius. São fornecidas, também, informações sobre outras espécies conhecidas dos subgêneros C. (Melacentris) e C. (Ptilotopus), nas quais se nota um mimetismo muito interessante de colorido da pilosidade (Figs. 3-4,5,8). As espécies $C$. frieseana nom. nov. e $C$. melanosara sp. nov. pertencem ao subgênero C. (Melacentris), e C. melampoda sp. nov. e C. erythrotricha sp. nov., a C. (Ptilotopus). Para separar as fêmeas destes subgêneros basta reparar nas placas basitibial e pigidial, duplas no primeiro e simples no segundo; as áreas glabras no dorso do tórax, também, são um bom distintivo para os dois subgêneros, principalmente para as fêmeas. Também o formato das mandíbulas logo distingue machos e fêmeas destes dois subgêneros, sendo os dentes mais encurtados ou, em parte, suprimidos em C. (Ptilotopus).

A sigla d indica o diâmetro do ponto e dp quantos diâmetros de ponto tem o intervalo entre os mesmos; $\boldsymbol{\mu}$ micra ou micron, tamanho em milésimos de mm; os valores numéricos entre ( ) são dados em centésimos de mm, caso não haja indicação expressa do contrário. DZUP: Coleção de Entomologia Pe J. S. Moure, Departamento de Zoologia, Universidade Federal do Paraná, Curitiba-PR.

\section{Centris (Melacentris) frieseana nom. nov.} (Fig. 1)

Centris friesei Ducke, 1902: 363, non Schrottky, 1902.

Espécie de tamanho avantajado. O comprimento total 28,65 mm e da asa anterior $20.00 \mathrm{~mm}$; largura da cabeça 8,65 mm e de T2 10,33 mm.

Toda preta, com algo de castanho muito escuro no abdome e nas pernas. O labro, para o ápice, um pouco mais castanhoescuro, mais claro para a base, nas áreas malares e base das mandíbulas; estas com pequena mancha amarela no dente apical; algo de pardo no labro, na área malar e na porção apical do clípeo. Tégulas pretas, ligeiramente acastanhadas; asas muito escuras, praticamente pretas, com reflexos azul-violeta na área basal celulada e um pouco mais esverdeada na porção apical livre de células; às vezes, com manchas um pouco verdes irregulares sobre o reflexo violáceo. Os fêmures e a base do primeiro tergo de um castanho muito escuro.

Pilosidade inteiramente preta menos no segundo tergo; este, todo coberto por densa pilosidade amarelo-clara, deixando estreitíssima margem preto-pilosa na base. A pilosidade fina e densa sobre todo o corpo, formada de pêlos curtos, curtoplumosos, cobrindo a pontuação; atrás do propódeo, mais longa e de um castanho muito escuro. As tégulas no terço externo posterior glabras, com pontos finos.

Pontuação pilígera coberta pela densa pilosidade. Em certas áreas, onde a pilosidade é falha, pode-se ver a pontuação densa, os pontos com cerca de $30-40 \mu$, com alguns intervalos irregulares, lisos, quase tão grandes como o diâmetro dos pontos. No clípeo a superfície com reticulado muito delicado, mais lisa e acompanhando o bordo anterior com alguns micropontos; no disco o terço médio superior um pouco deprimido, o médio levemente inchado e o inferior discal mais plano; entre os pontos mais grossos algumas rugas irregulares; o clípeo, ao longo do meio, menos pontuado, os pontos, como antes, com cerca de 30-40 $\mu$ de diâmetro, a pontuação um pouco mais

1. Contribuição ${ }^{\circ} 1335$ do Departamento de Zoologia, Universidade Federal do Paraná.

2. Departamento de Zoologia, Universidade Federal do Paraná. Caixa Postal 19020, 81531-980 Curitiba-PR, Brasil. Professor Emérito. Bolsista do CNPq. 
adensada nos declives laterais.

Cabeça mais larga que longa (865:665); olhos grandes, pouco menos longos que duas vezes sua largura máxima (565: 312); a distância interorbital superior um pouco menor que a inferior (360: 400) e a interocelar quase igual à ocelorbital, menos de duas vezes o diâmetro do ocelo médio (92:90:d58). O clípeo bastante mais longo que sua distância ao bordo anterior do ocelo médio (280:160); a distância interalveolar quase quatro vezes a alveolorbital (132: 39). As mandíbulas quadridentadas, sendo o terceiro dente o menor. $\mathrm{O}$ escutelo levemente tuberculado o que, freqüentemente, fica mais evidente pela depilação das duas elevações na porção central. Essas elevações verticais ao plano superior do escutelo, e não alongadas e abertas para trás como em C.(Ptilotopus). A placa basitibial dupla, a superior excêntrica, um pouco deslocada para trás, mas sem sobrepassar o bordo posterior. A fímbria pré-pigidial densa e bem regular. A placa pigidial dupla, a inferior subtriangular, com os bordos ligeiramente reentrantes e o ápice curtamente truncado; a placa superior em triângulo mais aberto para a base e de contornos mais regulares.

Material examinado. Seis exemplares fêmeas, todos coletados no Pará, à distância de menos de $200 \mathrm{Km}$. de Belém, na porção Oriental do Amazonas. Dois exemplares são de Belém, dois de Moju, no Rio Cairi e dois de Mocajuba, no Rio Tocantins.

DuCKe (1902) publicou esta espécie em homenagem a Friese, porém, C. (Melacentris) furcata friesei Schrottky, já tinha sido publicada pouco antes, neste mesmo ano. Em Belém-PA, encontrei um exemplar, no Museu Goeldi em 1955, com esse nome manuscrito por Ducke, provavelmente o exemplar-tipo.

Desejando conservar a homenagem de Ducke a Friese, deilhe o nome de Centris (M.) frieseana nom. nov.

\section{Centris (Melacentris) melanosara sp. nov.}

(Fig. 2)

Comprimento total aproximado $23,25 \mathrm{~mm}$; da asa anterior 17,5 mm; largura da cabeça 7,08; de T2 9,15 mm.

De côr predominantemente ferrugínea, sendo mais clara a pilosidade do tórax, particularmente na extremidade posterior. A cor da cabeça e das pernas preta, igualmente preto-pilosas, particularmente a enorme escopa que reveste as pernas posteriores. As tégulas ferrugíneas; as asas pardacentas, mais intensamente para a base; a venação mais para o pardo, com C, Sc e $\mathrm{R}$ um pouco mais escuras.

Pilosidade na cabeça inteiramente preta, mesmo nas genas e labro e as longas cerdas inferiores da base das mandíbulas. Tórax dorsalmente com pilosidade fulvo-amarelada muito densa, chegando anteriormente até os lobos pronotais; para os mesoe metepisternos pardo-fulva. Preta nos tarsos anteriores; pardoescura nas tíbias e tarsos médios, nos apicais pardo-fulva, como nas pernas do segundo par passando a mais escura ventralmente; nas tíbias e tarsos posteriores bem desenvolvida e densa, inteiramente preta. Nos lados do propódeo e extremidade posterior do escutelo mais clara. Um pouco mais longa e menos densa nos dois primeiros tergos, mais densa nos seguintes, de um colorido mais para o palha amarelento, $\mathrm{e}$ ferrugíneo mais claro, em certa luz, nos últimos tergos e nos esternos.

Pontuação nos lados do clípeo bastante forte e densa com pontos até $60 \mu$; os intervalos mais fortemente tesselados e rugosos, no terço médio discal quase sem pontos e a superfície mais fracamente tesselada (50x), com uma carena longitudinal imperfeita; o restante da face coberta pela pilosidade mais densa; na fronte a pontuação densa e a tesselação bastante forte; diante dos ocelos uma área lisa e sem pontos; a carena frontal relativamente fraca quase desaparecendo na área lisa em frente ao ocelo médio; as áreas ocelorbitais mates, com retículo muito fino junto aos ocelos, um pouco mais lisas, e atrás com mais pontuação. O tórax e os tergos com a pontuação inteiramente coberta pela densa pilosidade.

Cabeça claramente mais larga que longa (725:500). Olhos quase duas vezes mais longos que largos (410:220), mais curtos que a interorbital superior e esta que a inferior (320:350); o clípeo bastante convexo, mais longo que a distância clipeocelar (240:180); a distância interocelar quase igual à ocelorbital (80:85:d50), porém 5/8 do diâmetro do ocelo médio. O escapo bastante grosso, duas vezes mais longo que seu diâmetro máximo (120:60), claramente mais curto que o flagelômero basal (120:190).

Holótipo fêmea, de "Viçosa, Minas Gerais, Brasil, XII-1944, Peter Wygodzinsky leg.” (DZUP).

A combinação de cores do tegumento e pilosidade separa facilmente de outras espécies deste subgênero. Assemelha-se muito à $C$. (Ptilotopus) melampoda sp. nov. pelo colorido, particularmente da escopa.

\section{Centris (Ptilotopus) melampoda sp. nov.}

(Fig. 7)

Fêmea, com o comprimento total aproximado de $28,8 \mathrm{~mm}$; a asa anterior com 17,85 mm; largura da cabeça 8,08 mm; do T2 $10,95 \mathrm{~mm}$

Ferrugínea; com a cabeça de colorido castanho um pouco escuro, o clípeo e labro mais para o amarelo; as mandíbulas de um castanho-escuro acentuado, com uma pinta amarela preapical; as antenas com o escapo, pedicelo e artículo basal pardo-ferrugíneos, os artículos distais mais escurecidos. O tórax pardo-escuro, acastanhado, o escutelo um pouco mais claroavermelhado; as pernas anteriores e médias mais para o ferrugíneo, as posteriores para um castanho-escuro. As tégulas ferrugíneas, escurecidas para a base; as asas moderadamente pardo-acastanhadas, mais escuras para a base. Propódeo e abdome um pouco mais para o castanho-avermelhado.

Pilosidade ocre-ferrugínea; na cabeça mais para o castanhoescuro; no tórax com tonalildade parcialmente amareloalaranjada; as pernas posteriores com a escopa bastante escura, quase preta. O propódeo e o abdome avemelhados, um pouco para o pardo nos tergos e um pouco mais para o ferrugíneoclaro nos esternos. 
Pontuação pilígera coberta pela pilosidade, menos as partes naturalmente descobertas no mesoscuto e escutelo, típicas de C. (Ptilotopus); no mesoscuto imperfeitamente subquadrada, com pequena reentrância média anterior; no escutelo as duas áreas subcirculares unidas anteriormente, fracamente alongadas e abertas para trás; nas axilas subtriangulares. Rala no disco do clípeo e no labro com uma carena média longitudinal lisa, o sulco médio anteriormente invadido pela pilosidade. Na base de T1 os pontos tão grandes como os intervalos, nos tergos seguintes a pontuação pilígera um pouco mais densa.

Cabeça mais larga que longa (808:750); os olhos grandes, mais curtos que duas vezes sua largura (525:270), com a interorbital inferior ligeiramente maior que a superior (100:103); menos de 1/5 do comprimento do olho; distância interocelar um pouco menor que a ocelorbital 61:68 e o diâmetro do ocelo médio menor (50); escapo mais longo que duas vezes seu diâmetro máximo(74:28). O clípeo deprimido na metade basal a depressão estreitando-se para baixo; o labro com uma carena brilhante ao longo do meio. A placa basitibial simples, estreita (40:11), densamente pilosa, rebordada; a placa pigidial aimples, muito estreita, com toda parte exposta glabra, o ápice em arco levemente ogival.

Holótipo fêmea, de "Manaus, Amazonas, Brasil, viii/1959, Claudionor Elias leg.” (DZUP).

Dei este nome ao exemplar mimético de Centris (Melacentris) melanosara sp. nov., para chamar a atenção sobre a escopa que é inteiramente preta ou muito escura. No restante é também mimético da referida espécie pela combinação das cores da pilosidade. Estas duas espécies pertencem a subgêneros diferentes.

Distingue-se facilmente de todas as espécies conhecidas de $C$. (Ptilotopus) pelo seu colorido predominantemente ferrugíneo quase uniforme e com as pernas pretas. A pilosidade do tórax tem uma tonalidade ferrugíneo-amarelenta caraterística, mais pálido-amarelada nas extremidades do escutelo e axilas.

\section{Centris (Ptilotopus) erythrotricha sp. nov.} (Fig. 6)

Fêmea, com o comprimento total aproximado de $25,82 \mathrm{~mm}$; da asa anterior 17,5 mm; largura da cabeça 7,41 mm; do T2 9,58 $\mathrm{mm}$.

Todo o corpo de um castanho-escuro, com o clípeo, labro e escapo um pouco mais avermelhados; as asas pardo-escuras, um pouco transparentes com fraco reflexo violáceo, mais evidente na porção distal sem células.

Pilosidade inteiramente ferrugínea, uniforme em todo corpo e pernas, inclusive a escopa tíbio-tarsal.

Pontuação encoberta pela densa pilosidade; no clípeo ligeiramente menos densa deixando ver os pontos com os intervalos intercalados ligeiramente maiores e mate-reticulados, deixando uma carena ao longo do meio menos evidente na extremidade basal do clípeo, e uma barra apical glabra; outra carena, um pouco mais forte no labro e com a pilosidade mais longa na porção distal. As mandíbulas negro-acastanhadas e sem mancha amarela preapical, curto-tridentadas, os dentes decrescentes do ápice para dentro; a área malar estreita, atrás mais larga (cerca de $40 \mathrm{~cm}$ ). Área discal glabra do mesoscuto muito densamente pontuada, os pontos cerca de $40 \mu$ e os intervalos mate-reticulados, uniformes; na porção anterior a pilosidade entra um pouco mais nessa área companhando a linha média deprimida; nas axilas a área glabra imperfeitamente triangular com a pontuação um pouco mais fina e parcialmente apagada; no escutelo a área glabra forma um $\mathrm{V}$ aberto para trás com os bordos posteriores um pouco arredondados, a pontuação e reticulado como na área glabra discal do mesoscuto. Os tergos inteiramente cobertos pela pilosidade curta e densa, deixando glabra a placa pididial muito estreita e longa. A escopa densamente fulvo-pilosa, de colorido igual ao do restante do corpo.

Cabeça mais larga que longa (741:608); os olhos grandes, mais longos que duas vezes sua largura (475: 205); a distância interorital superior praticamente igual a inferior (360:362); o clípeo bastante mais longo que sua distância ao ocelo médio (240:160). Escapo mais longo que largo (95:60), com o artículo basal do flagelo mais longo que os quatro artículos seguintes juntos (180:160); a distância interocelar ligeiramente maior que a ocelorbital, duas vezes o diâmetro do ocelo médio (100:105:d50). A placa basitibial pequena, simples, peluda, com o rebordo bem marcado; a placa pigidial glabra, longa e estreita, subparalela nos dois quintos distais terminando com a ponta arredondada.

O macho extremamente parecido com a fêmea, com a carena clipeal um pouco mais forte. A largura da cabeça maior que o comprimento (666:524), o olho um pouco mais curto que duas vezes sua largura (456:240); a distância interorbital inferior maior que a superior (260:300); a distância interocelar maior que a ocelorbital, esta pouco mais que o diâmetro do ocelo médio (80:56:d46).

Holótipo fêmea, de "Pucallpa, Peru, 3 de Julho de 1960" (DZUP). Parátipos: 1 fêmea e 1 macho, com os mesmos dados do holótipo (DZUP).

Parátipo fêmea ligeiramente menor que o holótipo, 25,0 mm, com a pilosidade do mesoscuto mais maltratada. A mandíbula aberta mostra bem os dentes muito curtos, descrescendo do apical para o interno, menor e mais curto que os anteriores. A carena clipeal um pouco mais forte e com alguns pontos maiores (cerca de 50 $\mu$ ) irregularmente dispersos; a área lisa diante do ocelo médio um pouco mais longa.

Muito parecida com Centris (Melacentris) rufohirta Friese 1900 (Fig. 4), que ocorre na mesma área zoogeográfica, sendo bastante comum em Loreto, Peru.

Centris (Melacentris) rhodoprocta Moure \& Seabra, 1961 (Fig. 3)

Centris analis Lepeletier, 1841: 152, non Fabricius, 1804.

Centris (Melacentris) rhodoprocta Moure \& Seabra, 1961 [“1960”]:110.

Esta espécie, descrita por LePELETIER (1841) como C. analis, 
1
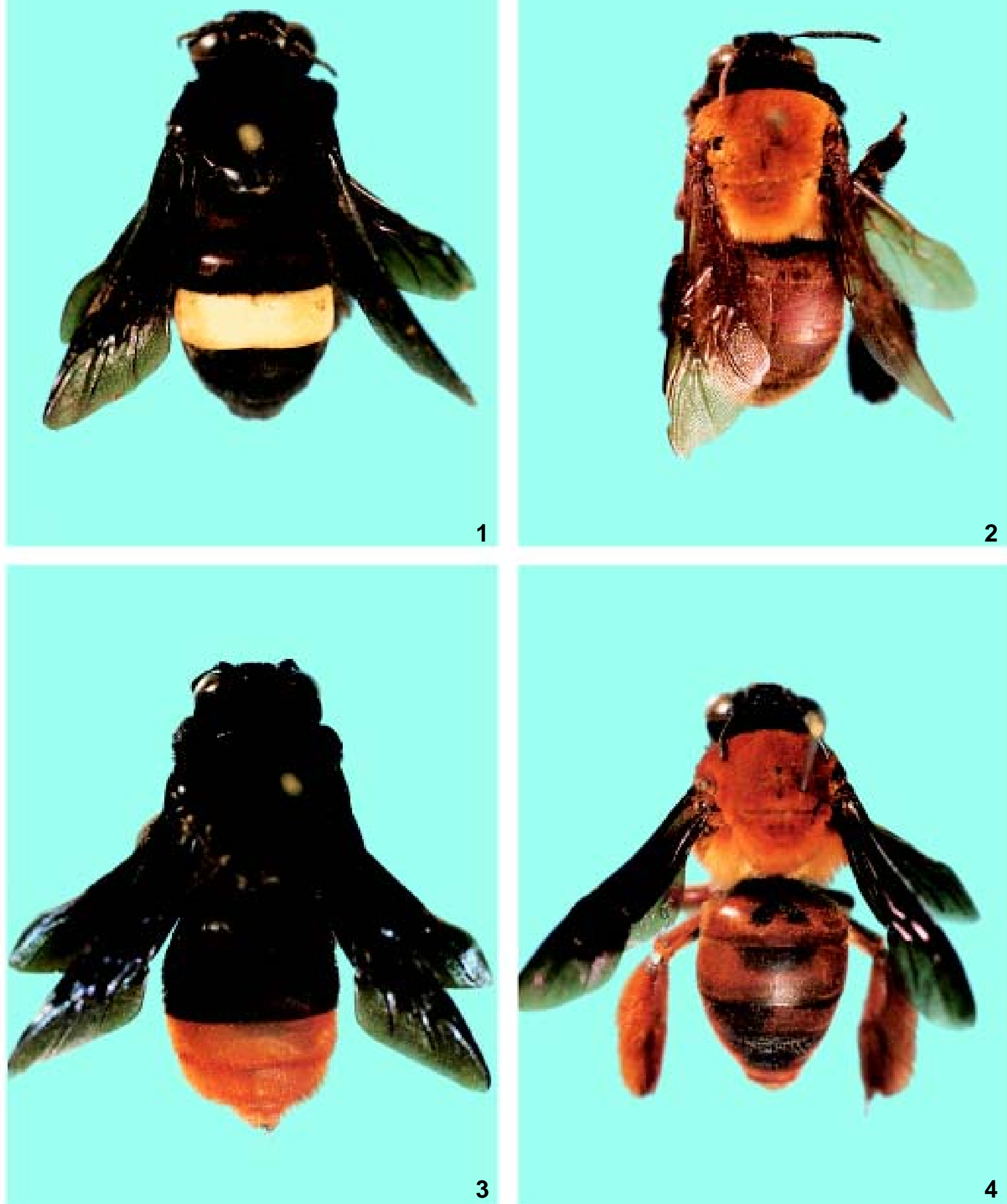

Figs. 1-4. Espécies de Centris (Melacentris): 1, C. (M.) frieseana nom. nov.; 2, C. (M.) melanosara sp. nov. (holótipo); 3, C. (M.) rhodoprocta Moure \& Seabra, 1961; 4, C. (M.) rufohirta Friese, 1900. 

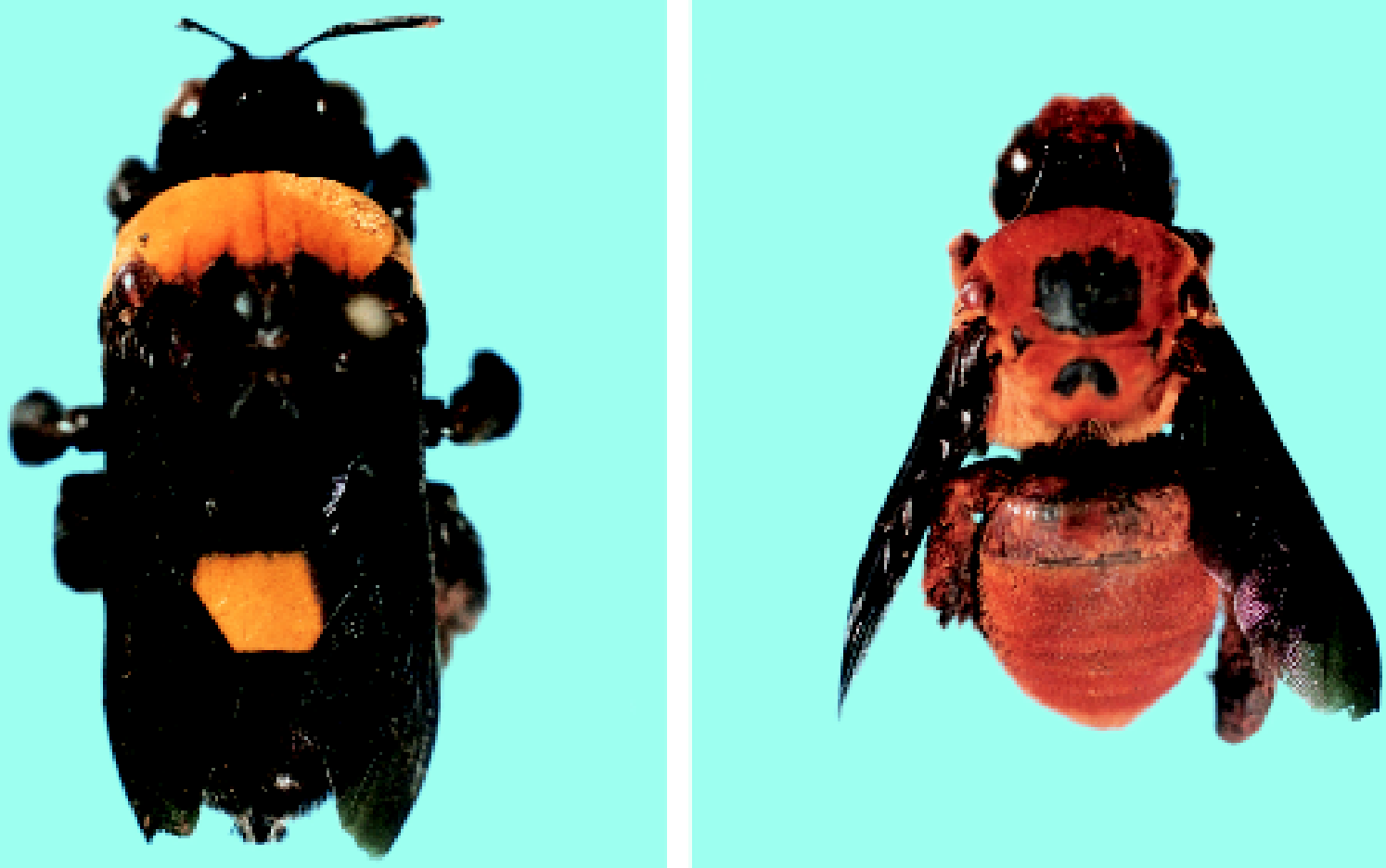

5
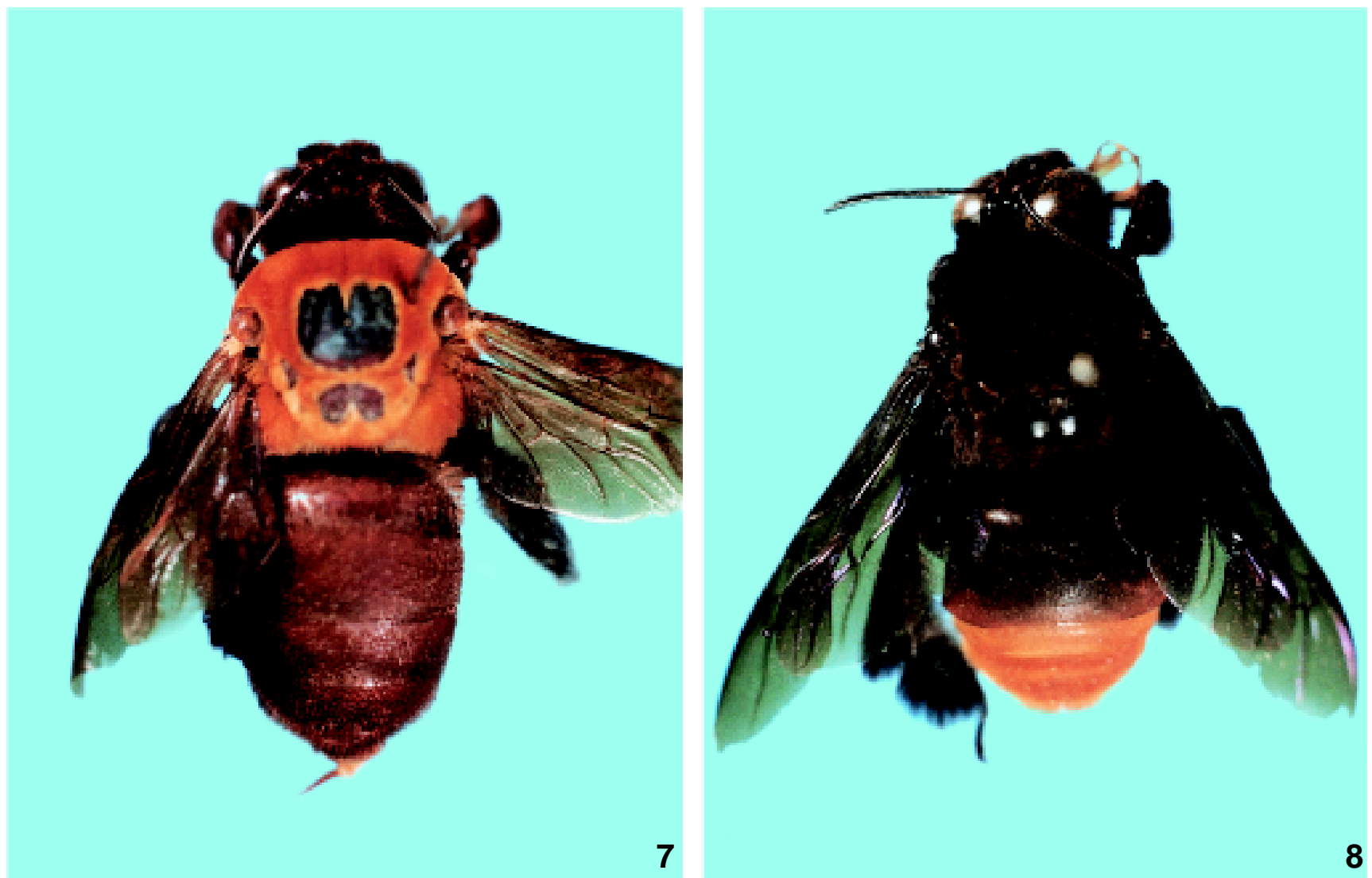

Figs. 5-8. Espécies de Centris (Ptilotopus): 5, C. (P.) americana Klug, 1810; 6, C. (P.) erythrotricha sp. nov. (holótipo); 7, C. (P.) melampoda sp. nov. (holótipo); 8, C. (P.) nobilis Westwood, 1840. 
é um sósia de C. (Ptilotopus) nobilis Westwood, 1840. Moure \& SEABRA (1961) puzeram-lhe o nome de C. (M.) rhodoprocta, e está aqui figurada para compará-la com a do macho de $C$. (Ptilotopus) nobilis Westwood, 1840 (Fig. 8). Estas duas espécies estavam confundidas pelo mimetísmo do colorido em várias coleções européias e norte-americanas com vários nomes. Ambas ocorrem na Amazônia.

Agradecimentos. Ao Prof. Albino M. Sakakibara pelas magníficas fotos e pela leitura crítica do trabalho.

\section{REFERÊNCIAS}

Ducke, A. 1902. Beobachtungen über Bienenbesuch, Erscheinungszeit etc. der bei Para vorkommenden Bienen. Allgemeine Zeitschrift für Entomologie 7: 360-367.

Fabricius, J. C. 1804. Systema Piezatorum, Brunsvigae: Reichard. $\mathrm{XIV}+[15\}-[440]+[1]-30$ pp.index appeared in 1805 according to Hedicke,1941. Mitteilungen der Deutchen Entomologischen Gesellschaft 10: 82-83.

Friese, H. 1900. Monographie der Bienengattung Centris (s.lat.) Annalen des k.k.naturhistorischen Hofmuseums 15: 237-350.

Moure, J. S. \& C. A. C. Seabra, 1961 [“1960”]. Sobre a identidade de algumas espécies de Centris (Hymenoptera - Apoidea). Revista Brasileira de Entomologia 9: 109-117.

Schrotткy, C. 1902. Hymenoptères Noveaux de l’Amérique Méridionale. Anales del Museo Nacional de Buenos Aires 7: 309-315. 